NOTES

\title{
Synthesis and Characterization of New Soluble Cardo Polyamides Derived from 2,2-Bis[4-(4-carboxyphenoxy)phenyl]norbornane
}

\author{
Der-Jang LiAw ${ }^{\dagger}$ and Been-Yang LiaW \\ Department of Chemical Engineering, \\ National Taiwan University of Science and Technology, \\ Taipei, Taiwan 106, Republic of China \\ (Received August 18, 2000; Accepted October 24, 2000)
}

KEY WORDS 2,2-Bis[4-(4-carboxyphenoxy)phenyl]norbornane / Polyamide / Crystallinity / Solubility / Thermal Analysis / Mechanical Properties /

Aromatic polyamides have been reported for high temperature resistance and excellent mechanical properties. $^{1,2}$ However, wholly aromatic polyamides, particularly those with para substituted rings, are quite intractable materials that do not melt and only dissolve in strong mineral acids such as concentrated sulfuric acid or in very polar aprotic solvents containing salts. Therefore, many efforts have been made to chemically modify the structures of these polymers to improve solubility and/or lowering transition temperatures to a range that facilitates processing in a melt. Several studies have been made to improve the solubility of polyamides such as addition of pendent groups to the polymeric backbone $\mathrm{e}^{3-5}$ and incorporation of bulky substituents ${ }^{6-10}$ within the parent chain.

Another successful approach to improve the processability of aromatic polyamide without extreme loss of outstanding properties is to introduce cardo, i.e., pendent loops, along the polymer backbone. ${ }^{11}$ The introduction of cardo groups creates amorphous polymers with characteristic features such as improved solubility and enhanced thermal stability as well as better mechanical and thermal properties. ${ }^{11,12}$ Our previous studies reported that incorporating cardo groups such as cyclododecylidene $\mathrm{e}^{13}$, adamantane $\mathrm{e}^{14,15}$, tricyclo $\left[5.2 .1 .0^{2,6}\right] \mathrm{de}-$ cane $^{16}$ into the backbone of polyamides resulted in polymers with enhanced solubility, processability and good thermal stability. ${ }^{13-16}$ The solubility and glass transition temperature of the polymers increased with stiffness and bulkiness of the cardo groups. ${ }^{13-16}$

The present study reports the synthesis of novel polyamides with pendent norbornyl groups along the polymer chain. The new dicarboxylic acid, 2,2-bis[4-(4carboxyphenoxy)phenyl]norbornane (BCAPN), containing norbornyl group was synthesized and polymerized with various diamines to prepare novel polyamides. The incorporation of stiff and bulky norbornyl group into polyamide backbones showed increase the solubility, thermal and mechanical properties of the polymers. The characterization of new polymers such as crystallinity, thermal, physical, and mechanical properties was made.

\section{EXPERIMENTAL}

\section{Materials}

Norcamphor (from Aldrich), $p$-chlorobenzonitrile (from ACROS), anhydrous potassium carbonate (from Merck), hydrazine monohydrate (from Merck), and $10 \%$ palladium on activated carbon $(\mathrm{Pd} / \mathrm{C}$, from Merck) were used as received 1,3-Phenylenediamine (DA1, from Merck) was purified by vacuum sublimation. 3,3',5,5'Tetramethyl-2,2-bis [ 4- ( 4-aminophenoxy ) phenyl ] propane $^{17}$ (DA2), 2,2-bis [4-(4-aminophenoxy)phenyl]adamantane ${ }^{14}$ (DA3), 5,5-bis [4-(4-aminophenoxy)phenyl]4,7-methanohexahydroindane ${ }^{16}$ (DA4) were synthesized and purified according to the method previously reported. ${ }^{14,16,17}$

\section{Monomer Synthesis}

2,2-Bis(4-hydroxyphenyl)norbornane (BHPN). Norcamphor $11.0 \mathrm{~g}(0.1 \mathrm{~mol}), 75 \mathrm{~g}(0.8 \mathrm{~mol})$ of phenol and 1 $\mathrm{mL}$ of 3-mercaptopropionic acid were introduced into a three-neck flask equipped with a condenser, magnetic stirrer, gas inlet, and thermometer. The reaction was heated to $80^{\circ} \mathrm{C}$ and purged with hydrogen chloride gas. After $30 \mathrm{~min}$, a dark red foamy material was obtained. The addition of hydrogen chloride gas was stopped and the reaction mixture was cooled. The mixture was allowed to stand at room temperature for $12 \mathrm{~h}$ during which time the mixture solidified. The solid mass was dispersed in $1 \mathrm{~L}$ water and the mixture was steam distilled to remove excess phenol and 3-mercaptopropionic acid leaving an aqueous suspension. The solid residue was collected from the mixture by filtration, and was recrystallized from toluene twice. The yield of BHPN was $70 \% ; \mathrm{mp} 196-197^{\circ} \mathrm{C}$ (literature ${ }^{11}: 199-200^{\circ} \mathrm{C}$ ).

2,2-Bis [ 4- (4-cyanophenoxy) phenyl] norbornane $(B C Y P N)$. A mixture of BHPN (10.3 g, $35 \mathrm{mmol}), p$ chlorobenzonitrile $(9.7 \mathrm{~g}, 72 \mathrm{mmol})$, potassium carbonate $(4.3 \mathrm{~g}, 77 \mathrm{mmol})$ and dry $N, N$-dimethylformamide (DMF, $20 \mathrm{~mL}$ ) was refluxed for $8 \mathrm{~h}$, cooled and poured into methanol-water ( $1: 1$ by volume). The crude product was recrystallized from ethanol twice. The yield was

\footnotetext{
${ }^{\dagger}$ To whom correspondence should be addressed (Phone: 886-2-27376638 or 886-2-27335050; Fax: 886-2-23781441 or 886-2-27376644; E-mail: liaw@ch.ntust.edu.tw).
} 
76\%; mp 142- $144^{\circ} \mathrm{C}$; Infrared (IR) $\left(\mathrm{KBr}, \mathrm{cm}^{-1}\right): 2216$ (CN), 1243 (COC); ${ }^{1} \mathrm{H}$ Nuclear magnetic resonance (NMR) $\left(400 \mathrm{MHz}\right.$ in Dimethyl sulfoxide (DMSO- $d_{6}$ ), ppm): $\delta=7.80-7.77$ (dd, $4 \mathrm{H}) ; 7.45-7.38$ (dd, $4 \mathrm{H}) ; 7.03$ $-6.97(\mathrm{~m}, 8 \mathrm{H}) ; 3.3-1.1(\mathrm{~m}, 10 \mathrm{H}) ;{ }^{13} \mathrm{C} \mathrm{NMR}(99 \mathrm{MHz}$ in DMSO- $\left.d_{6}, \mathrm{ppm}\right): \delta=162.4,153.0,152.8,149.9,146.1$, $135.7,130.5,129.5,120.7,120.5,119.6,118.8,105.7$, 105.7, 55.6, 44.0, 43.3, 37.6, 37.5, 29.1, 24.1. Anal. calcd for $\mathrm{C}_{33} \mathrm{H}_{26} \mathrm{O}_{2} \mathrm{~N}_{2}$ : C, 82.13\%; H, 5.43\%; N, 5.81\%; found: $\mathrm{C}, 81.95 \% ; \mathrm{H}, 5.27 \%$; N $5.63 \%$.

2,2-Bis [ 4- (4-carboxyphenoxy) phenyl] norbornane $(B C A P N)$. A mixture of $3.57 \mathrm{~g}(7.4 \mathrm{mmol})$ of dinitrile compound (BCYPN), $8.3 \mathrm{~g}$ of potassium hydroxide in 80 $\mathrm{mL}$ of ethanol and $80 \mathrm{~mL}$ of distilled water was stirred at $130^{\circ} \mathrm{C}$. Hydrogen peroxide $(30 \mathrm{~mL})$ was added dropwise over a period of $0.5 \mathrm{~h}$ to the suspension solution. After 4 days, the solution became clear and then was cooled, $\mathrm{pH}$ was adjusted by hydrochloric acid to near 3 . The white precipitate formed was collected by filtration, washed with methanol several times and reprecipitated from $N, N$-dimethylacetamide (DMAc) solution into methanol. The system was dried under vacuum at $80^{\circ} \mathrm{C}$ for $24 \mathrm{~h}$. The yield was $87 \%$; $\mathrm{mp} 273^{\circ} \mathrm{C}$ (by Differential Scanning Calorimeter (DSC)); IR $\left(\mathrm{KBr}, \mathrm{cm}^{-1}\right)$ : $2500-$ 3600 (C(O)O-H str.), 1674 ( $\mathrm{C}=\mathrm{O}$ str.), 1239 (C-O str.). ${ }^{1} \mathrm{H}$ NMR (400 MHz in DMSO- $\left.d_{6}, \mathrm{ppm}\right): \delta=12.79(\mathrm{~s}, 2 \mathrm{H})$; 7.93-7.91 (dd, $4 \mathrm{H}) ; 7.42-7.35$ (dd, $4 \mathrm{H}) ; 7.03-6.94(\mathrm{~m}$, $8 \mathrm{H})$; $3.30-1.02(\mathrm{~m}, 10 \mathrm{H}) ;{ }^{13} \mathrm{C}$ NMR $(99 \mathrm{MHz}$ in DMSO$\left.d_{6}, \mathrm{ppm}\right): \delta=168.2,162.3,162.2,153.8,153.5,149.5$, $145.6,132.7,130.4,129.4,126.2,126.1,120.3,120.1$, 118.1, 55.6, 44.1, 43.4, 37.6, 37.5, 29.2, 24.1, 18.3. Anal. calcd for $\mathrm{C}_{33} \mathrm{H}_{28} \mathrm{O}_{6}$ : C, 76.14\%; $\mathrm{H}, 6.43 \%$; found: $\mathrm{C}$, $75.98 \%$; $\mathrm{H}, 6.23 \%$.

\section{Preparation of Polymer}

A mixture of $0.625 \mathrm{~g}(1.2 \mathrm{mmol})$ of dicarboxylic acid BCAPN, $0.129 \mathrm{~g}$ (1.2 mmol) of diamine DA1, $0.3 \mathrm{~g}$ of calcium chloride, $0.9 \mathrm{~mL}$ of triphenyl phosphite (TPP), 0.9 $\mathrm{mL}$ of pyridine, and $5.0 \mathrm{~mL}$ of $\mathrm{N}$-methyl-2-pyrrolidinone (NMP) was heated with stirring at $100^{\circ} \mathrm{C}$ for $2 \mathrm{~h}$. After cooling, the reaction mixture was poured into excess methanol with constant stirring to produce a white stringy precipitate that was washed thoroughly with methanol and hot water. It was then extracted with hot acetone using a Soxhlet extractor and dried at $100^{\circ} \mathrm{C}$ under vacuum for $24 \mathrm{~h}$. The inherent viscosity of the polymer in DMAc was $1.49 \mathrm{dL} \mathrm{g}^{-1}$, as measured at $0.5 \mathrm{~g}$ $\mathrm{dL}^{-1}$ at $30^{\circ} \mathrm{C}$. IR (film, $\left.\mathrm{cm}^{-1}\right): 1650(\mathrm{C}=\mathrm{O}), 3284(\mathrm{~N}-\mathrm{H})$.

Other polyamides were prepared by similar procedure.

\section{RESULTS AND DISCUSSION}

\section{Synthesis of Dicarboxylic Acid}

The synthetic route of the new nobornyl-containing dicarboxylic acid monomer, 2,2-bis[4-(4-carboxyphenoxy) phenyl]norbornane (BCAPN), is shown in Scheme 1. The bisphenol compound, 2,2-bis(4-hydroxyphenyl)norbornane (BHPN) was prepared by acid-catalyzed condensation from norcamphor with excess phenol in the presence of hydrogen chloride. BHPN was reacted with $p$ chlorobenzonitrile in the presence of potassium carbonate to afford the dinitrile compound, 2,2-bis[4-(4cyanophenoxy)phenyl]norbornane (BCYPN), which was
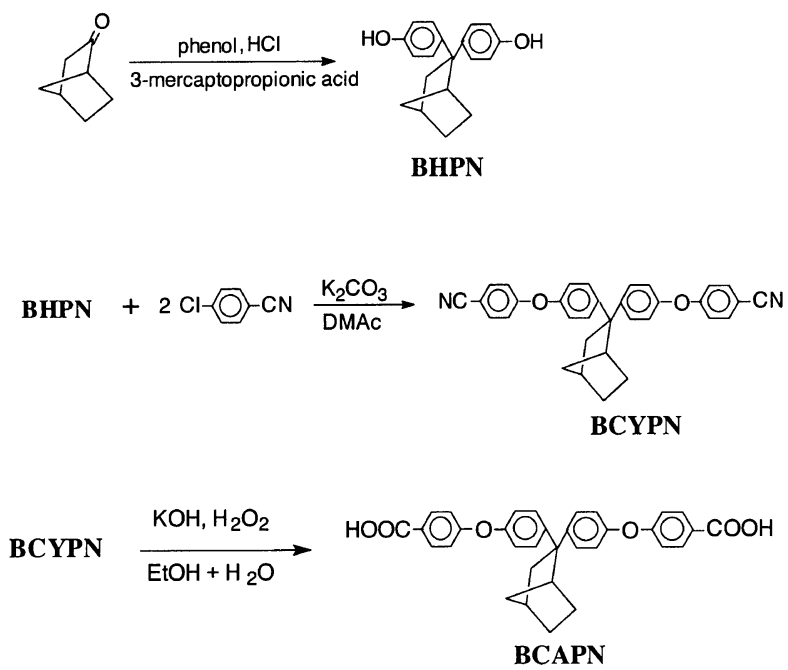

Scheme 1. Route for synthesis of 2,2-bis[4-(4-carobxyphenoxy)phenyl]norbornane (BCAPN).
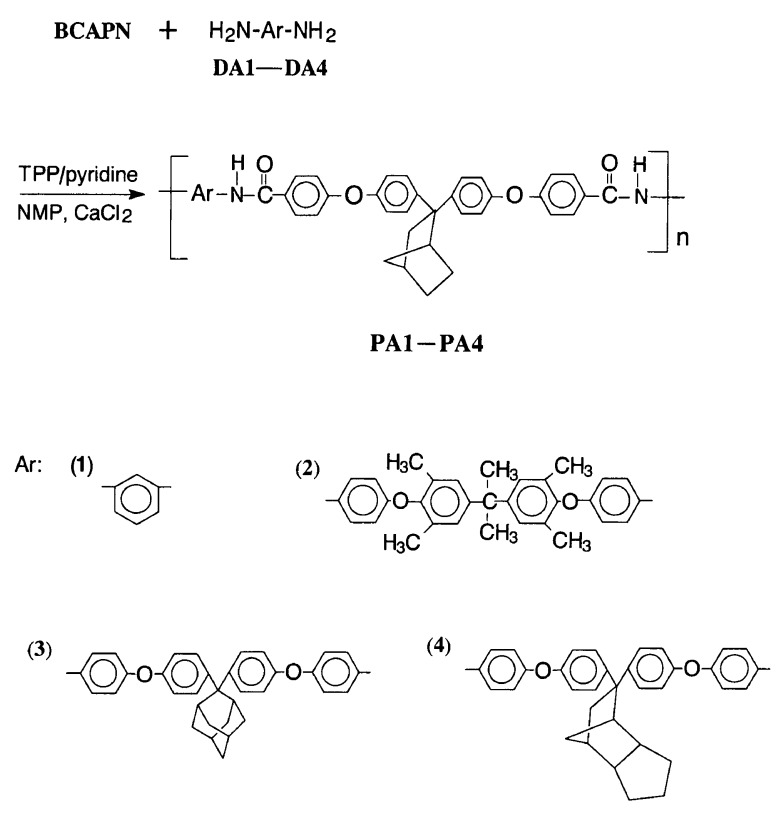

Scheme 2. Preparation of new cardo polyamides.

purified by recrystallization from ethanol twice. Hydrolysis of the dinitrile compound BCYPN to the dicarboxylic acid compound,2,2-bis[4-(4-carboxyphenoxy)phenyl]norbornane (BCAPN), was accomplished by potassium hydroxide as well as hydrogen peroxide in a mixture of ethanol and water. It was purified by reprecipitation from DMAc into methanol. Nitriles can be hydrolyzed to give either amides or carboxylic acids. The amide is formed initially, but since amides are hydrolyzed with acid or base, carboxylic acid is the more common product. When carboxylic acid is desired, the reagent of choice is a basic aqueous solution containing 6 to $12 \%$ hydrogen peroxide, although acid-catalyzed hydrolysis is frequently carried out. ${ }^{18}$ The structures of the synthetic compounds were identified by elemental analysis, IR, and NMR spectroscopy. The cyano group of compound BCYPN appeared from the peak at $2216 \mathrm{~cm}^{-1}$ in the IR spectrum. In the IR spectrum of BCAPN, cyano 
D.-J. Liaw and B.-Y. LiAW

Table I. Preparation, average molecular weights, and elemental analysis data for various polyamides

\begin{tabular}{|c|c|c|c|c|c|c|c|c|c|}
\hline \multirow{2}{*}{$\begin{array}{l}\text { Polymer } \\
\text { Code }\end{array}$} & \multirow{2}{*}{$\frac{\eta_{\text {inh }}{ }^{\mathrm{a}}}{\mathrm{dL} \mathrm{g}^{-1}}$} & \multirow{2}{*}{$\begin{array}{c}\text { Yield } \\
\%\end{array}$} & \multicolumn{2}{|c|}{$\mathrm{IR} / \mathrm{cm}^{-1}$} & \multicolumn{5}{|c|}{ Elemental analysis/\% } \\
\hline & & & $\mathrm{N}-\mathrm{H}$ & $\mathrm{C}=\mathrm{O}$ & & $\mathrm{C}$ & $\mathrm{H}$ & $\mathrm{N}$ & $\begin{array}{c}\text { Moisture } \\
\text { Intake in\% }\end{array}$ \\
\hline \multirow[t]{2}{*}{ PA1 } & 1.49 & 99 & 3284 & 1650 & Calcd & 77.37 & 5.56 & 4.63 & \\
\hline & & & & & Found & 77.85 & 5.68 & 4.51 & 2.10 \\
\hline \multirow{2}{*}{ PA2 } & 0.93 & 98 & 3286 & 1648 & Calcd & 77.72 & 6.35 & 2.81 & \\
\hline & & & & & Found & 77.99 & 6.38 & 2.68 & 2.56 \\
\hline \multirow[t]{2}{*}{ PA3 } & 1.14 & 97 & 3279 & 1651 & Calcd & 78.91 & 5.99 & 2.53 & \\
\hline & & & & & Found & 79.01 & 6.08 & 2.48 & 2.40 \\
\hline \multirow[t]{2}{*}{ PA4 } & 0.98 & 98 & 3280 & 1655 & Calcd & 78.62 & 6.04 & 2.68 & \\
\hline & & & & & Found & 78.89 & 6.10 & 2.55 & 2.46 \\
\hline
\end{tabular}

${ }^{\mathrm{a}}$ Measured in DMAc at $0.5 \mathrm{~g} \mathrm{dL}^{-1}$ at $30^{\circ} \mathrm{C}$.

stretching vibration disappeared, but broad $\mathrm{C}(\mathrm{O}) \mathrm{O}-\mathrm{H}$ absorption appeared in the region of $2500-3600 \mathrm{~cm}^{-1}$ and $\mathrm{C}=\mathrm{O}$ stretching absorption appeared at $1674 \mathrm{~cm}^{-1}$. NMR spectra data are listed in the experimental section. In the ${ }^{13} \mathrm{C}$ NMR spectrum, the carbon of the carboxyl group had resonance at $168.2 \mathrm{ppm}$. A broad peak attributed to the carboxylic acid proton was observed around $12.8 \mathrm{ppm}$ in the ${ }^{1} \mathrm{H}$ NMR spectrum , thus indicating the new dicarboxylic acid monomer prepared in this study to be consistent with the proposed structure.

\section{Synthesis of Polyamides}

New polyamides (PA1-PA4) were prepared by hosphorylation polycondensation of dicarboxylic acid BCAPN with aromatic diamines using triphenyl phosphite (TPP) and pyridine as condensing agents (Scheme 2). All polymerizations readily proceeded in homogeneous solution, indicating good polymer solubility in the polymerization media. Tough and stringy precipitates formed when viscous polymer solutions were trickled into the stirring methanol. All polymers were obtained in high yield (above 97\%) and inherent viscosities of $0.93-1.49 \mathrm{dL} \mathrm{g}^{-1}$ as measured in DMAc solution (Table I). Transparent, tough and flexible polymer films were obtained by casting from DMAc solution. IR spectra of the polyamides showed characteristic absorptions of amide groups at $1648-1650$ and $3279-3286 \mathrm{~cm}^{-1}$ (Table I).

Elemental analysis results of the polyamides are listed in Table I. Carbon of polyamides was less than that calculated for the proposed structures. Such difference may be attributed to amide group hygroscopic characteristics. ${ }^{3}$ Absorbed water of the polyamides ranged from $2.40-2.56 \%$. Corrected values correlated well with those calculated after found values had been corrected.

\section{Polymer Characterization}

Crystallinity of the cardo polyamides was estimated by wide-angle X-Ray diffractograms. Entire polymers exhibited amorphous patterns. The amorphous behavior of the cardo polyamides was attributed to bulky pendent groups which increased significantly disorder in polymer chains and therefore caused less chain packing.The norbornyl group decreased intermolecular force such as hydrogen bonding between polymer chains, causing decrease in crystallinity. ${ }^{19}$

Solubility of all polyamides is summarized in Table II.

Most of the polyamides exhibited good solubility in solvents such as NMP, DMAc, DMF, DMSO, pyridine, and cyclohexanone at room temperature or on heating at $70^{\circ} \mathrm{C}$, due to the pendent norbornyl group in the polymer backbone. Norbornyl groups disturbed dense chain packing of the polymer chain; consequently, solvent molecules penetrated easily to solubilize the chains. Polymer PA2 containing no ether group showed less solubility than the other polyamides. The solubility of two analogous poly Ref 1 with adamantyl group and Ref 2 with tricyclo[5.2.1.0 $0^{2,6}$ ] group ${ }^{15-16}$ is listed in Table II. Polymer PA3 with a norbornyl group showed better solubility than Ref 1 or Ref 2.

Thermal properties of the polyamides are summarized in Table III.

All polymers displayed distinct glass transition with the second heating of DSC traces, whereas endotherms or exotherms were completely lacking. These polyamides had glass transition temperatures $\left(T_{\mathrm{gs}}\right)$ of $231-266^{\circ} \mathrm{C}$. Polymer PA3 containing a pendent adamantane group exhibited the highest $T_{\mathrm{g}}$. In general, chain rigidity increased due to the pendent cardo group, which restricted free rotation of the polymer backbone. Hence, the obtained polymers showed high glass transition temperature. Polymer PA2 bearing a meta-linkage showed lower $T_{\mathrm{g}}$ than the other polyamides. TGA traces reveal all cardo polyamides not to decompose around or below $450^{\circ} \mathrm{C}$ in nitrogen or air. Decomposition temperatures of $10 \%$ weight loss $\left(T \mathrm{~d}_{10}\right)$ were from $468-523^{\circ} \mathrm{C}$ and $503-$ $553^{\circ} \mathrm{C}$ in nitrogen and air, respectively. $T \mathrm{~d}_{10}$ of the polymers in air was higher than in nitrogen. The higher $T \mathrm{~d}_{10}$ in air may reflect oxidation of alicyclic norbornyl groups, to form carbonyl groups, and cause weight gain. ${ }^{19}$ Adamantane-containing polymer PA 3 showed the highest $T \mathrm{~d}_{10}$ since adamantane is generally recognized as a highly thermally stable unit. ${ }^{9}$ Table II, it shows PA 3 to exhibit higher $T d_{10}$ than Ref 2.

The mechanical properties of the polymer films are summarized in Table III. The polymer films had tensile strength of 99-130 MPa, elongation at break of 9-15\% and tensile modulus of $2.1-3.2 \mathrm{GPa}$. Polyamide PA2 film containing flexible isopropylidene unit exhibited a yield point on stress-strain curves while the others did not. Polymer PA1 derived from 1,3-phenylenediamine showed the best mechanical properties. This may be due to PA1 being derived from DA1, which has no ether group and shows more stiffness than the others. Table II, shows PA3 to exhibit better mechanical properties than Ref 1 or Ref 2. 
Table II. Solubility of various polyamides ${ }^{\mathrm{a}}$

\begin{tabular}{|c|c|c|c|c|c|c|c|c|}
\hline \multirow{2}{*}{$\begin{array}{l}\text { Polymer } \\
\text { Code }\end{array}$} & \multicolumn{8}{|c|}{ Solubility $^{\mathrm{b}}$} \\
\hline & NMP & DMAc & $\mathrm{DMF}$ & DMSO & Pyridine & $\begin{array}{c}\text { Cyclo- } \\
\text { hexanone }\end{array}$ & $\mathrm{THF}$ & Chloroform \\
\hline PA1 & ++ & ++ & +- & +- & ++ & + & - & - \\
\hline PA2 & ++ & ++ & ++ & + & ++ & ++ & ++ & +- \\
\hline PA3 & ++ & ++ & ++ & + & ++ & ++ & + & - \\
\hline PA4 & ++ & ++ & ++ & + & ++ & ++ & + & - \\
\hline Ref 1 & ++ & ++ & ++ & + & + & + & +- & - \\
\hline Ref 2 & ++ & ++ & ++ & + & ++ & + & +- & - \\
\hline
\end{tabular}

${ }^{a}$ Measured at $0.5 \mathrm{~g} \mathrm{dL}^{-1}$ at $30^{\circ} \mathrm{C} .{ }^{\mathrm{b}}$ Solubility: ++ : soluble at room temperature; + : soluble on heat at $70^{\circ} \mathrm{C} ;+-:$ partial soluble at $70^{\circ} \mathrm{C}$ -: insoluble at $70^{\circ} \mathrm{C}$. Abbreviations: NMP: $N$-methyl-2-pyrrolidinone; DMAc: $N, N$-dimethylacetamide; DMF: $N, N$-dimethylformamide; DMSO: dimethylsulfoxide; THF: tetrahydrofuran.

Ref 1:

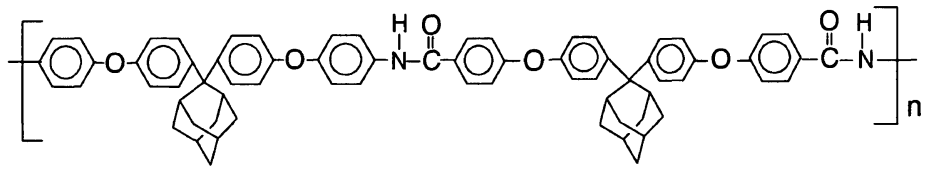

Ref 2:

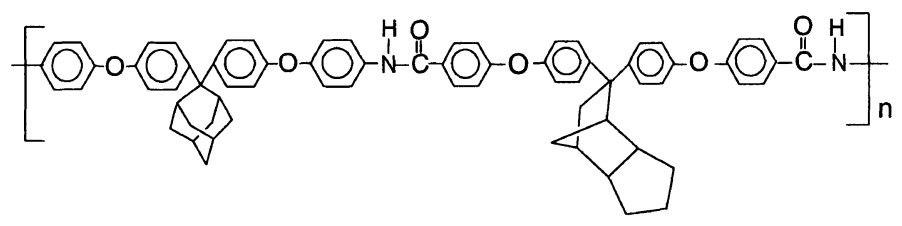

Table III. Thermal and mechanical properties of various polyamides

\begin{tabular}{|c|c|c|c|c|c|c|c|}
\hline \multirow{3}{*}{$\begin{array}{c}\text { Polymer } \\
\text { Code }\end{array}$} & \multirow{3}{*}{$\frac{\text { DSC }}{T_{\mathrm{g}}{ }^{\mathrm{a} /} \mathrm{C}}$} & \multirow{2}{*}{\multicolumn{2}{|c|}{$\begin{array}{c}\text { TGA } \\
T \mathrm{~d}_{10}^{\mathrm{b}} /{ }^{\circ} \mathrm{C}\end{array}$}} & \multirow{3}{*}{ 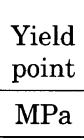 } & \multirow{3}{*}{$\begin{array}{c}\begin{array}{c}\text { Tensile } \\
\text { strength }\end{array} \\
\mathrm{MPa}\end{array}$} & \multirow{3}{*}{$\begin{array}{c}\begin{array}{c}\text { Elongation } \\
\text { at break }\end{array} \\
\%\end{array}$} & \multirow{3}{*}{$\begin{array}{c}\begin{array}{c}\text { Tensile } \\
\text { modulus }\end{array} \\
\mathrm{GPa}\end{array}$} \\
\hline & & & & & & & \\
\hline & & In $\mathrm{N}_{2}$ & In Air & & & & \\
\hline PA1 & 231 & 468 & 507 & $-^{c}$ & 130 & 15 & 3.2 \\
\hline PA2 & 251 & 479 & 506 & 116 & 103 & 10 & 2.1 \\
\hline PA3 & 266 & 523 & 537 & $-^{c}$ & 91 & 10 & 2.4 \\
\hline PA4 & 261 & 498 & 503 & - $^{\mathrm{c}}$ & 90 & 10 & 2.4 \\
\hline Ref 1 & 275 & 536 & 553 & $-^{c}$ & 89 & 9 & 2.2 \\
\hline Ref 2 & 269 & 515 & 523 & $-^{c}$ & 78 & 8 & 2.0 \\
\hline
\end{tabular}

${ }^{a}$ Glass transition temperature $\left(T_{\mathrm{g}}\right)\left({ }^{\circ} \mathrm{C}\right)$ measured by DSC at heating rate of $20^{\circ} \mathrm{C} \mathrm{min}^{-1}$. ${ }^{\mathrm{b}}$ Temperature at which $10 \%$ weight loss was recorded on TGA at a heating rate of $20^{\circ} \mathrm{C} \mathrm{min}^{-1}$. ${ }^{\mathrm{c}}$ No yield point observed from stress-strain curve.<smiles>[R10]C=[R10][H]</smiles>

\section{CONCLUSIONS}

The authors synthesized a new norbonyl-containing dicarboxylic acid, BCAPN. Novel cardo polyamides were prepared by direct polymerization from BCAPN with various diamines. Due to the incorporation of pendent norbornyl and cardo groups, polyamides were amorphous with excellent solubility and thermal stability, high glass transition temperature as well as mechanical properties. The polymer containing adamantane showed high thermal stability. The polymer from 1,3phenylenediamine showed excellent mechanical properties. Accordingly, the present polyamides may be considered as new processable high-temperature materials.

Acknowledgment. The authors thank the National Science Council of the Republic of China for supporting this work under grant NSC 89-2216-E 011-008. 


\section{REFERENCES}

1. P. E. Cassidy, "Thermally Stable Polymer", Marcel Dekker, Inc., New York, N.Y., 1980.

2. A. H. Frazer, "High Temperature Resistant Polymers", John Wiley \& Sons Ltd., New York, N.Y., 1968.

3. D. J. Liaw, B. Y. Liaw, and C. M. Yang, Macromolecules, 32, 7248 (1999).

4. F. Akutsu, M. Inoki, K. Araki, Y. Kasashima, K. Naruchi, and M. Miura, Polym. J., 29, 529 (1997).

5. A. E. Lozano, J. de Abajo, J. G. de la Campa, and J. Preston, J. Polym. Sci., Part A: Polym. Chem., 33, 1987 (1995).

6. D. J. Liaw and B. Y. Liaw, Macromol. Symp., 122, 343 (1997).

7. H. J. Jeong, Y. Oishi, M. A. Kakimoto, and Y. Imai, J. Polym. Sci., Part A: Polym. Chem., 28, 3193 (1990).

8. D. J. Liaw and B. Y. Liaw, J. Polym. Sci., Part A: Polym. Chem., 36, 1069 (1998).

9. H. Yagci and L. J. Mathias, Polym. Prepr. (Am. Chem. Soc., Div. Polym. Chem. ) 39, 262 (1998).

10. I. K. Spiliopoulos, J. A. Mikroyannidis, and G. M. Tsivgoulis,
Macromolecules, 31, 522 (1998).

11. V. V. Korshak, S. V. Vinogradova, and Y. S. Vygodski, J. Macromol. Sci., Rev. Macromol. Chem. Phys., C11, 45 (1974).

12. S. S. Vibhute, M. D. Joshi, P. P. Wadgaonkar, A. S. Patil, and N. N. Maldar, J. Polym. Sci., Part A: Polym. Chem., 35, 3227 (1997).

13. D. J. Liaw and B. Y. Liaw, Polym. Adv. Technol., 9, 740 (1998).

14. D. J. Liaw and B. Y. Liaw, Macromol. Chem. Phys., 200, 1326 (1999).

15. D. J. Liaw, B. Y. Liaw, and C. Y. Chung, Acta Polym., 50, 135 (1999).

16. D. J. Liaw, B. Y. Liaw, and C. Y. Chung, Macromol. Chem. Phys., 200, 1023 (1999).

17. D. J. Liaw and B. Y. Liaw, Macromol. Chem. Phys., 199, 1473 (1998).

18. J. March, "Advanced Organic Chemistry", John Wiley \& Sons Ltd., 4th ed, New York, N.Y., 1992, pp 887-888.

19. D. J. Liaw, B. Y. Liaw, J. R. Chen, and C. M. Yang, Macromolecules, 32, 6860 (1999). 